DFPARTAMRNTO DE TFIRAPEUTICA, FARMACOLOGIA F ARTE DE FORMULAR

Diretor: Prof. Dr. Gabriel Sylvestre Teixeira de Carvalho

\title{
MODIFICAÇÃO DA AÇÃO DA D-TUBOCURARINA E DA SUCCINILCOLINA EM BUFO ICTERICUS SOB INFLUÊNCIA DA TEMPERATURA (Nota prévia)
}

\author{
(INFLUENCE OF TEMPERATURE ON THE ACTION OF \\ D-TUBOCURARINE AND SUCCINYLCHOLINE UPON \\ BUFO ICTERICCS) - (Previous note)
}

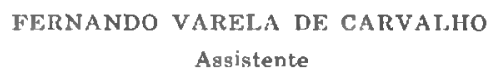

Está hoje estabelecido que as drogas curarizantes não agem necessàriamente através de um mesmo mecanismo, embora tenham sua atividade relacionada, de algum modo, com o mediador químico da junção neuromuscular.

A interferência da acetilcolina, na transmissão do influxo nervoso ao músculo estriado, ocasionando contração dêste, semelhantemente à produzida pela estimulação do respectivo nervo motor, foi evidenciada por BROWN, DALE e FELDBERG (1936), bem como DALE e cols. (1936) verificaram não haver impedimento da liberação de acetilcolina junto à placa motora, durante a curarização.

A reciprocidade da ação exercida pela acetilcolina e as substâncias curarizantes revestiu-se, conseqüentemente, de especial importância, e dos estudos feitos conclue-se que estas podem agir na junção neuromuscular, seja provocando uma despolarização prolongada, seja estabilizando o estado de polarização da placa motora terminal.

As drogas curarizantes, de modo geral, devem ser subdivididas em duas classes principais:

a) as estabilizadoras do estado de polarização da placa motora terminal, aumentando dêste modo o limiar da placa à ação da acetilcolina mediador, encontrando na d-tubocurarina um exemplo típico; 
b) as que promovem despolarização prolongada da placa motora, reproduzindo a ação típica da acetilcolina durante um período dilatado de tempo, têm como exemplo a succinilcolina.

Esta diferença, quanto ao modo de ação dos agentes curarizantes tem sido demonstrada por várias técnicas.

A experiência feita por MAROTTA e CARMINATI (1954) usando agentes anticolinesterásicos como a fisostigmina, neostigmina, sais fenólicos do amônio quartenário, em associação com succinilcolina ou d-tubocurarina, revelou prolongamento de ação da succinilcolina e antagonismo da d-tubocurarina.

A ac atilcolina é hidrolizada por uma enzima específica chamada cclinesterase (STEDMAN \& STEDMAN, 1932), bem como pela sl.ccinilcolina (BOVET-NITTI, 1949), numa proporçāo diretamente relacionada com a quantidade da enzima.

Em virtude de trabalho anterior (CARVALHO, VEIGA e CHIEFFI - 1957), no qual verificamos haver em bovinos, redução do teor de colinesterase sérica pelo aquecimento por irradiação, a ponto que causasse hipertcrmia, resolvemos verificar qual o comportamento das drogas curarizantes representantes dos dois tipos de mecanismos mencionados, frente ao aumento de temperatura.

\section{MATERIAL E MÉTOIOS}

Utilizamos como animal de prova o sapo (Bufo ictericus) por dispensar a respiração artificial durante a fase de curarização.

Organizamos 4 grupos de 8 animais. Dêstes grupos dois foram tratados com succinilcolina e os restantes com d-tubocurarina.

Os grupos tratados com d-tubocurarina sofreram as seguintes subdivisões:

A) Injeção de d-tubocurarina no saco linfático, na dose de $0,750 \mu \mathrm{g} 100 \mathrm{~g}$ de pêso corporal, mantendo-se os animais à temperatura ambiente.

B) Injeção de d-tubocurarina no saco linfático na dose de $0,750 \% \mathrm{~g} 100 \mathrm{~g}$ de pêso corporal, colocando-sc a seguir os animais em estufa regulada a $38^{\circ} \mathrm{C}$.

Os grupos tratados com succinilcolina sofreram as seguintes subdivisões: 
C) Injeção de succinilcolina no saco linfático na dose da $8 \mathrm{mg} 100 \mathrm{~g}$ de pêso corporal mantendo-se os animais à temperatura ambiente.

D) Injeção de succinilcolina no saco linfático na dose de $8 \mathrm{mg} 100 \mathrm{~g}$ de pêso corporal colocando-se a seguir os animais em estufa regulada a $38^{\circ} \mathrm{C}$.

Para a obscrvação dos resultados obtidos, com a injeção das drogas em aprêço, verificamos o tempo decorrido da injeção da droga até o início do relaxamento muscular completo, com ausência dos movimentos respiratórios, e aquêle em que se notava a volta dos movimentos respiratórios. Esta observação foi feita por inspeção dos animais mantidos à temperatura ambiente, bem como nos cclocados dentro da estufa, através da porta de vidro das mesmas.

Além destas provas, executamos também em outro grupo de animais, observadas as mesmas condições térmicas citadas o registro gráfico da contração muscular. Para tal, após a destruição total do sistema nervoso, cerebral e medular, fizemos a preparação neuro-muscular, ciático-gastrocnêmio, "in situ".

A estimulação elétrica aplicada ao nervo ciático era originária de um circuito farádico, tendo 3 volts, cujos estímulcs máximos apresentavam a freqüência de 1 por segundo.

Os animais colocados na cstufa tinham o fio de linha que liga o tendão de Aquiles à alavanca inscritora passando através de um des crifícios próprios para adaptação de termômetros.

Após o preparo do animal, era o mesmo colocado na estufa, prèviamente regulada à temperatura de $38^{\circ} \mathrm{C}$, e iniciada a estimulação elétrica, registrando-se as contrações do músculo gastriccnêmio. Logo após o início do registro acima referido, injetamos no saco linfático as drogas em estudo. O resultadc obtido pode ser observado nos gráficos anexos, representativos das experiências com d-tubocurarina e do succinilcolina.

\section{RESULTADOS}

Os dadcs obtidos com animais sujeitos às temperaturas da estufa e ambiente, no que se refere ao tempo decorrido após a injeção e duração do efeito podem ser condensados nos quadros seguintes. 


\section{QUADRO I}

Grupo A - Animais mantidos à temperatura de $15^{\circ} \mathrm{C}$, injetados com d-tubocurarina na dose de $0,750 \mathrm{y.g} / 100 \mathrm{~g}$ de pêso corporal

\begin{tabular}{|c|c|c|c|c|}
\hline \multirow{2}{*}{$\begin{array}{l}\text { N." do } \\
\text { sapo }\end{array}$} & \multirow{2}{*}{$\begin{array}{l}\text { Pêso } \\
\text { (g) }\end{array}$} & \multirow[b]{2}{*}{ Sexo } & \multicolumn{2}{|c|}{$\begin{array}{l}\text { Relaxamento muscular completo } \\
\text { com ausência de reflexos e } \\
\text { movimentos respiratórios }\end{array}$} \\
\hline & & & $\begin{array}{l}\text { Inicio } \\
\text { (minuto) }\end{array}$ & $\begin{array}{l}\text { Primeiros sinais } \\
\text { do } \\
\text { desaparecimento } \\
\text { (minuto) }\end{array}$ \\
\hline 4 & 36,5 & M & 14 & 60 \\
\hline 6 & 52,5 & $\mathbf{M}$ & 7 & 70 \\
\hline 28 & 39,0 & $F$ & 12 & 63 \\
\hline 8 & 38.0 & $\mathbf{M}$ & 11 & 60 \\
\hline 30 & 42,0 & $\mathbf{F}$ & 9 & 71 \\
\hline 21 & 36,0 & $\mathrm{~F}^{\prime}$ & 13 & 68 \\
\hline 12 & 31,0 & M & 9 & 90 \\
\hline 9 & 41,0 & $\mathbf{M}$ & 7 & 80 \\
\hline
\end{tabular}

QUADRO II

Grupo B - Animais mantidos em estufa a $38^{\circ} \mathrm{C}$, injetados com d-tubocurarina na dose de 0,750 j.g/100 $\mathrm{g}$ de péso corporal

\begin{tabular}{|c|c|c|c|c|}
\hline \multirow{2}{*}{$\begin{array}{l}\text { N. }{ }^{\circ} \text { do } \\
\text { sapo }\end{array}$} & \multirow{2}{*}{$\begin{array}{l}\text { Pêso } \\
\text { (g) }\end{array}$} & \multirow[b]{2}{*}{ Sexo } & \multicolumn{2}{|c|}{$\begin{array}{l}\text { Relaxamento muscular completo } \\
\text { com ausência de reflexos e } \\
\text { movimentos respiratórios }\end{array}$} \\
\hline & & & $\begin{array}{l}\text { Inicio } \\
\text { (minuto) }\end{array}$ & $\begin{array}{l}\text { Primeiros sinais } \\
\text { do } \\
\text { desaparecimento } \\
\text { (minuto) }\end{array}$ \\
\hline 2 & 36,5 & $\mathbf{M}$ & - & - \\
\hline 23 & 40,0 & $\mathbf{F}$ & - & - \\
\hline 3 & 40,0 & $\mathbf{M}$ & - & - \\
\hline 7 & 47,0 & $\mathbf{M}$ & - & - \\
\hline 31 & 42,7 & $\mathbf{F}$ & - & - \\
\hline 27 & 35,0 & $\mathrm{~F}$ & - & - \\
\hline 10 & 40,0 & $\mathbf{M}$ & - & - \\
\hline 11 & 51,0 & $\mathbf{M}$ & - & - \\
\hline
\end{tabular}


QUADRO III

Grupo C - Animais mantidos à temperatura de $17^{\circ} \mathrm{C}$, injetados com succinilcolina na dose de $8 \mathrm{mg} / 100 \mathrm{~g}$ de pêso corporal.

\begin{tabular}{|c|c|c|c|c|}
\hline \multirow{2}{*}{$\begin{array}{l}\text { N. }{ }^{\circ} \text { do } \\
\text { sapo }\end{array}$} & \multirow{2}{*}{$\begin{array}{l}\text { Pĉso } \\
\text { (g) }\end{array}$} & \multirow{2}{*}{ Sexo } & \multicolumn{2}{|c|}{$\begin{array}{l}\text { Relaxamento muscular completo } \\
\text { com ausência de reflexos e } \\
\text { movimentos respiratórios }\end{array}$} \\
\hline & & & $\begin{array}{l}\text { Inicio } \\
\text { (minuto) }\end{array}$ & $\begin{array}{l}\text { Primeiros sinais } \\
\text { do } \\
\text { desaparecimento } \\
\text { (minuto) }\end{array}$ \\
\hline 32 & 38,0 & $\mathbf{M}$ & - & - \\
\hline 17 & 38,5 & $\mathbf{F}$ & - & - \\
\hline 24 & 42.0 & $\mathbf{M}$ & - & - \\
\hline 27 & 40.5 & $\mathbf{M}$ & - & - \\
\hline 19 & 40,0 & $F$ & - & - \\
\hline 20 & 56,0 & $\mathrm{~F}$ & - & - \\
\hline 1 & 43,0 & $F$ & - & - \\
\hline 5 & 52,0 & $F$ & - & - \\
\hline
\end{tabular}

QUADRO IV

Grupo D - $\Lambda$ nimais mantidos em estufa a $38^{\circ} \mathrm{C}$, injetados com succinilcolina na dose de $8 \mathrm{mg} / 100 \mathrm{~g}$ de pêso corporal.

\begin{tabular}{|c|c|c|c|c|}
\hline \multirow{2}{*}{$\begin{array}{l}\text { N." do } \\
\text { sapo }\end{array}$} & \multirow{2}{*}{$\begin{array}{l}\text { Pêso } \\
\text { (g) }\end{array}$} & \multirow[b]{2}{*}{ Sexo } & \multicolumn{2}{|c|}{$\begin{array}{l}\text { Relaxamento muscular completo } \\
\text { com ausência de reflexos e } \\
\text { movimentos respiratórios }\end{array}$} \\
\hline & & & $\begin{array}{l}\text { Inicio } \\
\text { (minuto) }\end{array}$ & $\begin{array}{c}\text { Primeiros sinais } \\
\text { do } \\
\text { dosaparecimento } \\
\text { (minuto) }\end{array}$ \\
\hline 14 & 52,0 & $F$ & 17 & 32 \\
\hline 16 & 43,8 & $\mathbf{F}$ & 20 & 35 \\
\hline 29 & 41,0 & $\mathbf{M}$ & 18 & 41 \\
\hline 25 & 40,5 & $\mathbf{M}$ & 17,30 & 36 \\
\hline 26 & 39,0 & $\mathbf{M}$ & 19 & 32 \\
\hline 18 & 39,5 & $\mathrm{~F}$ & 16 & 34 \\
\hline 13 & 50,0 & $\mathbf{F}$ & 19 & 43 \\
\hline 15 & 46,0 & $\mathbf{F}$ & 14 & 38 \\
\hline
\end{tabular}


No que se refere aos grupos de animais, dos quais cbtivemos o registro gráfico das contrações musculares por excitação do ciático, temos:

- Figura 1 -

No traçado superior, registro das contrações musculares do gastrocnêmio por excitação do ciático, estando o animal em t:emperatura ambiente de $15^{\circ} \mathrm{C}$ e pesando $50 \mathrm{~g}$. (A).

No traçado médio, registro idêntico, estando o animal em estufa à temperatura de $38^{\circ} \mathrm{C}$. Pêso do animal $49 \mathrm{~g}$. (B).

No traçado inferior - tempo $=1 \mathrm{seg}$.

As setas indicam o momento em que foi injetado, nc saco linfático, a dose de $0,750 \% \mathrm{~g} 100 \mathrm{~g}$ de pêso corporal, de d-tubccurarina.

Os espaços brancos, intermediários, representam urn tempo çecorrido de 10 minutos cada um.

\section{- Figura 2 -}

No traçado superior, registro das contrações de gastrocnêmio por excitação do ciático, estando o animal em tempcratura ambiente de $17^{\circ} \mathrm{C}$ e pesando $45 \mathrm{~g}$.

No traçado médio, registro idêntico, estando o animal $\mathrm{em}$ temperatura de $38^{\circ} \mathrm{C}$ e pesando $46 \mathrm{~g}$.

No traçado inferior - tempo $=1 \mathrm{seg}$.

As setas indicam o momento em que foi injetado no saco linfático, a dose de $8 \mathrm{mg} / 100 \mathrm{~g}$ de pêso corporal, de succinilcolina. Os espaços em branco, intermediários, representam um tempo decorrido de 10 minutos cada um.

\section{COMENTARIOS F CONCLUSÕES}

Existem drcgas - como a succinilcolina, por exemplo -- capazes de reproduzir o tipo de ação da acetilcolina na placa motora, porćm de modo mais brusco e prolongacio do que esta, causando despolarização que repercute na atividade motora do músculo esquelético. Esta influência mascara o efeito do mediador químico liberado pelo influxo que percorre o nervo, disto resultando uma forma especial de bloqueio ao nível da junção neuromuscular. Nestas condições, drogas de ação do tipo da succinilcolina, a própria acetilcolina ou agentes que impeçam a sua inativação no organismo, produzem um efcito semelhante na placa motora, diferindo, contudc, na intensidade, velocidade e duração do efeito desporalizante da placa motora, por elas produzido. 

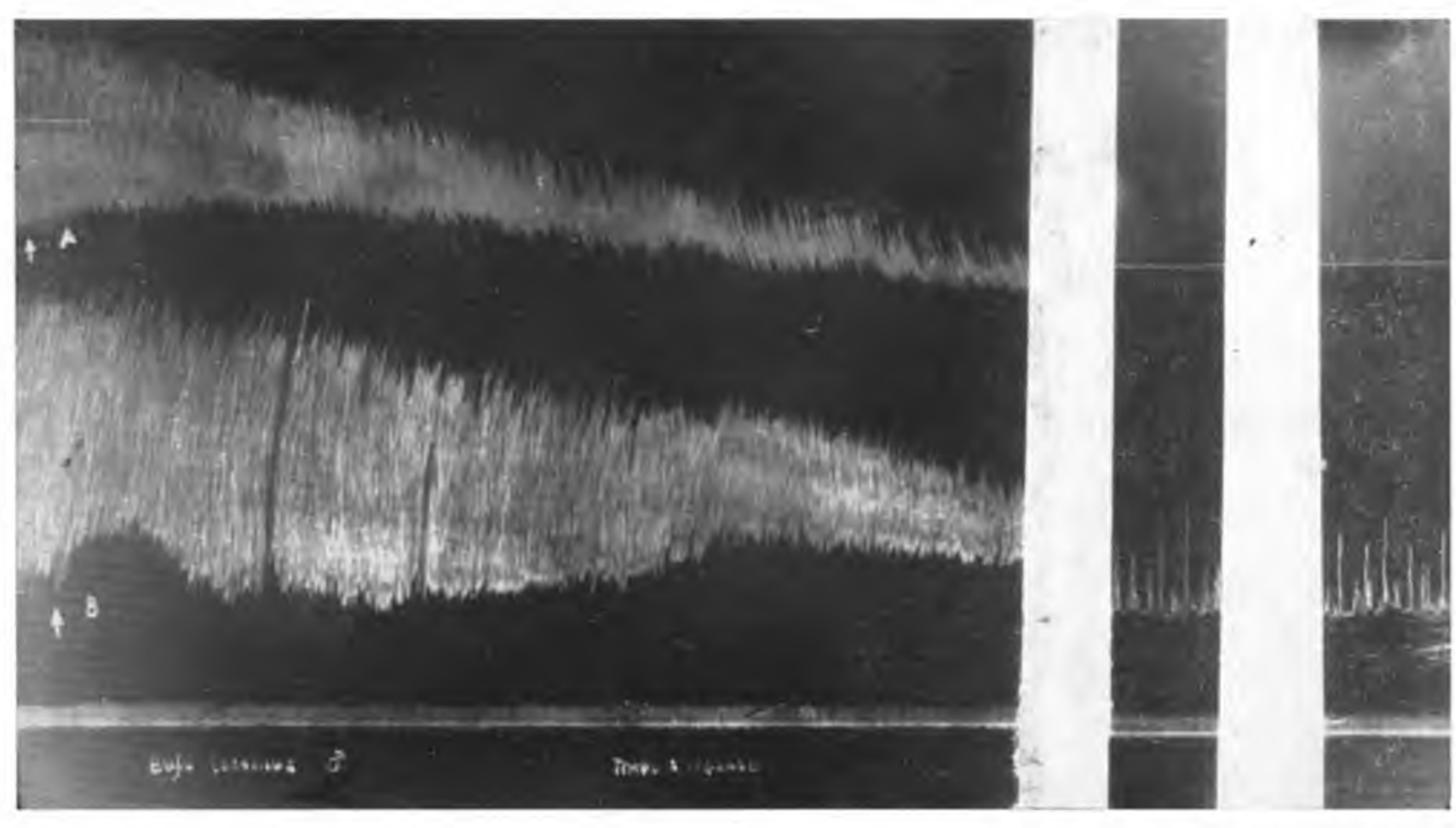

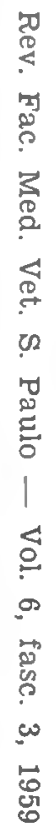

Fig. 1 - Sapo injetado corm d-tubocurarina

1) Em cima fora da estufa $\mathrm{T}^{\circ}=15^{\circ} \mathrm{C}(50 \mathrm{~g})$

3) Em baixo dentro da estufa $T^{n}=38^{\circ} \mathrm{C}(49 \mathrm{~g})$ 


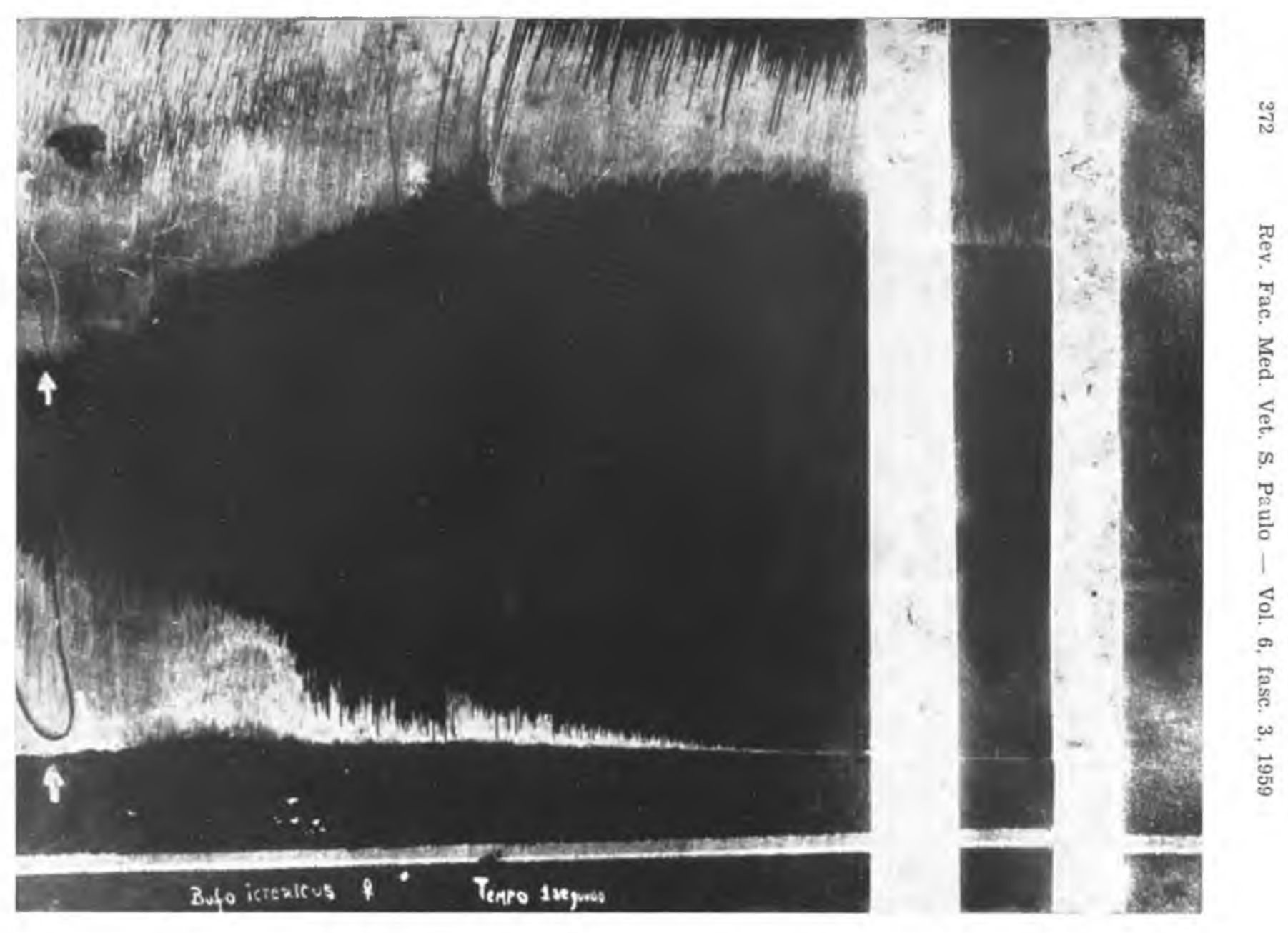

ig. 2 - Sapo injetado com succinilcolina.

Em cima fora da estufa $\mathrm{T}^{\mathrm{O}}=17^{\circ} \mathrm{C}(45 \mathrm{z})$

Em baixo dentro da estufa $\mathrm{T}^{\circ}=38^{\circ} \mathrm{C}(46 \mathrm{~g})$ 
Tal não é observado com outro tipo de bloqueador do influxo nervoso, na junção neuro-muscular, como a d-tubocurarina. Esta, por estabilização do potencial da placa motora, aumenta o seu limiar ao medidor quimico acetilcolina.

Por essa razão, as drogas que agem por impedir a inativação da acetilcolina, são antagônicas da d-tubocurarina.

Cumpre assinalar ,terem CAMBA e COSTA (1945) demonstrado um aumento da ação bloqueadora neuro-muscular da succinilcolina pelo DFP (diisopropil fluorofosfato), substância que inibe a colinesterase, e a d-tubocurarina, por seu turno, não apresentou modificação da ação curarizante por essa droga.

LUCAS e MILES (1955) verificaram por meio da administração de agente anticolinesterásico no macaco rhesus, depressão respiratória mais intensa com a succinilcolina de que com a d-tubocurarina.

Além das drogas conceituadas como anticolinesterásicas - fisostigmina, neostigmina, ésteres, fosfônicos, etc. - há outras substâncias capazes de apresentar efeito paralelo. DAVIS e cols. (1955) notaram a diminuição da colinesterase por influência do $\mathrm{CO}_{2:}$, intessificando destarte o efeito da succinilcolina.

A intenção do nosso trabalho é verificar a influência da temperatura ambiente como modificadora da ação da d-tubocurarina e da succinilcolina, em Bufo ictericus.

Ora, é de "conhecimento antigo" que a estação do ano pode exercer influência na resposta do coração ao estímulo vagal, em animais poicilotermos, respondendo o sapo mais intensamente no verão da que no inverno.

BROWN (1954) verificou em gato, maior eliminação de acetiicolina a $39^{\circ} \mathrm{C}$ do que a $20^{\circ} \mathrm{C}$, quando da estimulação do gânglio mesentérico inferior.

CARVALHO, VEIGA e CHIEFFI (1957) verificaram, em câmara climática, redução do teor de pseudocolinesterase em bovinos, correlacionada com a hipertermia nêles provocada, pelo aumento de temperatura ambiente. Reduzindo a hipertermia, o teor de pseudocolinesterase, supõe-se lògicamente, haver acúmulo de mediador químico liberado pelos nervos colinérgicos, podendo desta forma interferir no bloqueio provocado por drogas curarizantes segundo sejam os seus mecanismos. 
Nesta nota prévia, pelos resultados obtidos verificamos a ação diferente do comportamento das drogas - succinilcolina e d-tubocurarina - em Bufo ictericus frente ao aumento da temperatura ambiente.

\section{SUMMARY}

When and elevation of temperature acts on toads (Bufo ictericus) it enlarges the action time of succinylcholine and diminishes the action of d-tubocurarine.

\section{BIBLIOGRAFIA}

Bovet-NiTTI, F. - 1949 - Degradazione di alcune sostanze curarizzanti per azione di colinesterasi. R. C. Ist. Sup. Sanit., 12:138

Brown, G. L. - 1954 - The effect of temperature on the release of acetylcholine from sympathetic ganglia. J. Physiol., 124:26

Brown, G. L. - Dale, H. H. - Feldberg, W. - 1936 - Reactions of normal mammalian muscle to acetylcholine and to eserine. J. Physiol., $87: 394$

Camba, R. - Costa, E. - 1954 - Sull'influsso colencsterasi e del disopropilfluorosfato nei riguardi dell'attivitá curarica della succinilcolina. Arch. Sci. Biol,, 38:119

Carvalho, F. V. - Veiga, J. S. - Chifffi A. - 1957 - Modificação da quantidade de pseudocolinesterase em bovinos mantidos em ambiente de alta temperatura. Ciên. e Cult., 9 (4):221

Dale, H. H. - Feldeerg, W. - Vogt, M. - 1936 - Release of acetylcholine at voluntary motor nerve endings. J. Physiol., 86:353

Davis, D. A. - Ellis, F. G. - Reese, N. O. - Grosskreutz, D. C. 1955 - The prolonged effect of succinylcoline and some possible explanation for these phenomena. Anesthesiology, 16(3):333

LUCAs, B. G. B. - Miles, S. - 1955 - Antichelinesterase and muscle relaxants. Brit. Med. J., (4913):579

Marotta, M. - Carminati, G. M. - 1954 - Prolungamento dell'ativitá curarizanti della succinilcolina per azione di alcuni anticolinesterasici.Arch. Inter. Pharmacodyn., 98:255

Stedman, E. - Stedman, E. - 1932 - Studies on the relationship between chemical constitution and physiological action: The inhibitory action of certain synthetic urethanes on the activity of esterases. Bioch. $J ., 26: 1214$ 